\title{
Glyoxal uptake on ammonium sulphate seed aerosol: reaction products and reversibility of uptake under dark and irradiated conditions
}

\author{
M. M. Galloway ${ }^{1}$, P. S. Chhabra ${ }^{2}$, A. W. H. Chan ${ }^{2}$, J. D. Surratt ${ }^{3}$, R. C. Flagan ${ }^{2,4}$, J. H. Seinfeld ${ }^{2,4}$, and F. N. Keutsch ${ }^{1}$ \\ ${ }^{1}$ Dept. of Chemistry, University of Wisconsin-Madison, Madison, WI, USA \\ ${ }^{2}$ Dept. of Chemical Engineering, California Institute of Technology, Pasadena, CA, USA \\ ${ }^{3}$ Dept. of Chemistry, California Institute of Technology, Pasadena, CA, USA \\ ${ }^{4}$ Dept. of Environmental Science and Engineering, California Institute of Technology, Pasadena, CA, USA
}

Received: 7 October 2008 - Published in Atmos. Chem. Phys. Discuss.: 12 December 2008

Revised: 14 May 2009 - Accepted: 19 May 2009 - Published: 25 May 2009

\begin{abstract}
Chamber studies of glyoxal uptake onto ammonium sulphate aerosol were performed under dark and irradiated conditions to gain further insight into processes controlling glyoxal uptake onto ambient aerosol. Organic fragments from glyoxal dimers and trimers were observed within the aerosol under dark and irradiated conditions. Glyoxal monomers and oligomers were the dominant organic compounds formed under the conditions of this study; glyoxal oligomer formation and overall organic growth were found to be reversible under dark conditions. Analysis of highresolution time-of-flight aerosol mass spectra provides evidence for irreversible formation of carbon-nitrogen $(\mathrm{C}-\mathrm{N})$ compounds in the aerosol. We have identified $1 \mathrm{H}$-imidazole2-carboxaldehyde as one C-N product. To the authors' knowledge, this is the first time $\mathrm{C}-\mathrm{N}$ compounds resulting from condensed phase reactions with ammonium sulphate seed have been detected in aerosol. Organosulphates were not detected under dark conditions. However, active photochemistry was found to occur within aerosol during irradiated experiments. Carboxylic acids and organic esters were identified within the aerosol. An organosulphate, which had been previously assigned as glyoxal sulphate in ambient samples and chamber studies of isoprene oxidation, was observed only in the irradiated experiments. Comparison with a laboratory synthesized standard and chemical considerations strongly suggest that this organosulphate is glycolic acid sulphate, an isomer of the previously proposed glyoxal sulphate.
\end{abstract}

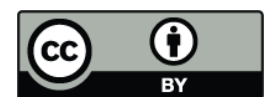

Correspondence to: F. N. Keutsch (keutsch@wisc.edu)
Our study shows that reversibility of glyoxal uptake should be taken into account in SOA models and also demonstrates the need for further investigation of C-N compound formation and photochemical processes, in particular organosulphate formation.

\section{Introduction}

Organic aerosol has been detected in substantial concentrations in urban and rural atmospheres (Zhang et al., 2007). Secondary organic aerosol (SOA) contributes significantly to particulate matter, though current models considerably underestimate SOA formation (de Gouw et al., 2005; Heald et al., 2005; Volkamer et al., 2006). In order to understand the possible health and climate effects of particulate matter, it is critical that the physical and chemical models of SOA formation be improved. Glyoxal (GL) is produced by a wide variety of biogenic and anthropogenic volatile organic compounds (VOCs), many of which are SOA precursors, and is considered a tracer for SOA formation. One current model estimates global GL production of $45 \mathrm{Tg} / \mathrm{yr}$, with roughly half due to isoprene photooxidation (Fu et al., 2008), and another estimates $56 \mathrm{Tg} / \mathrm{yr}$ of global GL production with $70 \%$ being produced from biogenic hydrocarbon oxidation (Myriokefalitakis et al., 2008). In addition to acting as a tracer for SOA formation, GL has been suggested as a direct contributor to SOA (Sorooshian et al., 2006; Volkamer et al., 2007, 2009; Carlton et al., 2007; Ervens et al., 2008; Fu et al., 2008). A study comparing observed and modelled GL has suggested that GL could contribute at least $15 \%$ of the SOA

Published by Copernicus Publications on behalf of the European Geosciences Union. 
in Mexico City (Volkamer et al., 2007), while a study using the GEOS-Chem model found the modelled GL contribution to SOA to be $2.6 \mathrm{Tg}$ C/year out of a total of $29 \mathrm{Tg}$ C/year (Fu et al., 2008).

Despite existing research aimed at elucidating SOA formation by GL, further quantification of SOA yields as a function of conditions such as relative humidity, irradiation, gasphase GL mixing ratio, and seed aerosol composition and $\mathrm{pH}$ are required in order to allow for the application of laboratory findings to ambient conditions. On a more fundamental level, it is desirable to achieve a detailed understanding of the processes contributing to SOA formation from GL as a function of the above conditions. GL is also promising as an interesting model system for compounds that can yield SOA via purely physical absorption processes and via complex condensed phase processes, such as oligomerization, organosulphate formation, condensation, and photochemical reactions.

The standard models that have been employed to explain organic gas-particle partitioning have generally assumed physical absorption processes (Pankow, 1994a,b; Odum et al., 1996). On this basis, GL, the smallest dicarbonyl, should have virtually no SOA yield because of its high vapour pressure (220 Torr at $20^{\circ} \mathrm{C}$, Kielhorn et al., 2004). However, GL partitions strongly to aqueous condensedphase systems, which is reflected in a surprisingly high effective Henry's law constant, $K_{\mathrm{H}, \mathrm{aq}}^{*}=3.6 \times 10^{5} \mathrm{M} / \mathrm{atm}$ for seawater (Zhou and Mopper, 1990) and $4.19 \times 10^{5} \mathrm{M} / \mathrm{atm}$ in water (Ip et al., 2009). The effective Henry's law constant of GL is higher than that of atmospherically relevant monocarboxylic acids including glyoxylic acid, $K_{\mathrm{H}, \mathrm{aq}}^{*}=1 \times 10^{4} \mathrm{M} / \mathrm{atm}$ (Ip et al., 2009), the acid that results from oxidation of one of the aldehyde groups in GL. Glycolic acid, an isomer of glyoxal monohydrate, also has a lower effective Henry's law constant of $2.83 \times 10^{4} \mathrm{M} / \mathrm{atm}$ (Ip et al., 2009). The high effective Henry's law constant of GL has been explained by the hydration of the aldehyde groups, producing an effectively lower vapour pressure species in aqueous solution. In addition to the physical absorption processes, particle-phase chemical reactions have been identified as a possible driving force for uptake. Carbonyl containing species are known to participate in aldol, acetal, and esterification reactions, which form low volatility compounds that add to SOA mass. Field and laboratory studies have also yielded evidence for the formation of high molecular weight products within SOA (Gross et al., 2006; Reinhardt et al., 2007; Denkenberger et al., 2007) and it is well known that GL will polymerize in the presence of water (Whipple, 1970; Loeffler et al., 2006).

These properties of GL, together with its production via oxidation of many VOCs, have inspired chamber investigations into GL partitioning onto a variety of seed particles (Jang et al., 2002; Liggio et al., 2005a,b; Kroll et al., 2005; Corrigan et al., 2008; Volkamer et al., 2009). Liggio et al. (2005b) have demonstrated reactive uptake of GL onto several different types of seed aerosol using an Aero- dyne aerosol mass spectrometer (AMS). This study suggested that GL uptake onto ammonium sulphate (AS) aerosol is irreversible and enhanced with acidified seed. However, Kroll et al. (2005) observed negligible acid effect and reversible GL uptake onto AS seed aerosol that is possibly controlled by ionic strength. The authors concluded that GL uptake obeys a modified effective Henry's Law at equilibrium $\left(K_{\mathrm{H}, \mathrm{AS}}^{*}=2.6 \times 10^{7} \mathrm{M} / \mathrm{atm}\right.$; using a density of $1 \mathrm{~g} / \mathrm{cm}^{3}$ to convert volume growth to organic mass and normalizing by the seed volume). Both Liggio et al. (2005b) and Kroll et al. (2005) observed hydration and oligomerization of GL within aerosol and, in addition, Liggio et al. (2005b) proposed irreversible formation of the organosulphate of GL (GL sulphate) to explain certain peaks in the AMS mass spectra. Volkamer et al. (2009) demonstrated that acetylene is an SOA precursor and estimated that almost all particle phase organic growth was due to its oxidation product, GL. SOA yields were shown to correlate with the liquid water content (LWC) of the AS seed. Therefore, the authors introduced a modified definition of molarity, calculating GL concentrations with respect to LWC fraction of the seed volume, which gave $K_{\mathrm{H}, \mathrm{AS}}^{* *}=1.65 \times 10^{8} \mathrm{M} / \mathrm{atm}$. Evaluating the data from Kroll et al. (2005) in this manner gives $K_{\mathrm{H}, \mathrm{AS}}^{* *}=1.07 \times 10^{8} \mathrm{M} / \mathrm{atm}$. However, in addition to the larger effective Henry's law constant in the study of Volkamer et al. (2009), this uptake in the presence of $\mathrm{OH}$ radicals and UV light was achieved in $90 \mathrm{~s}$ compared to many hours under dark conditions in the work by Kroll et al. (2005).

The difference between the Henry's law constant of water and AS aerosol is substantial and the reasons for this are not well understood. Recently, Ip et al. (2009) found that the effective Henry's Law increases with increasing sulphate concentration. At a sodium sulphate ionic strength of $0.03 \mathrm{~mol} / \mathrm{L}(\mathrm{M}), K_{\mathrm{H}}^{*}=2.40 \times 10^{7} \mathrm{M} / \mathrm{atm}$. This is 50 times higher than $K_{\mathrm{H} \text {,aq }}^{*}$ and 12 times higher than with a sodium chloride ionic strength of $0.05 \mathrm{M}$. Ip et al. (2009) concluded that the presence of sulphate has a greater effect on the effective Henry's Law than ionic strength alone. Increasing the ionic strength of sulphate to $0.225 \mathrm{M}$ increases the $K_{\mathrm{H}}^{*}$ to the point that it could not be measured, a value suggested to be $\geq 10^{9} \mathrm{M} / \mathrm{atm}$. This sulphate concentration is still substantially lower than that in the AS aerosol studies, but the suggested effective Henry's law constant is substantially larger than for the AS aerosol. It is possible that with increasing sulphate concentration and thus decreasing LWC, $K_{\mathrm{H}}^{*}$ of GL first increases up to a maximum and then decreases again. A similar effect was found by Ip et al. (2009) for sodium chloride solutions. This indicates that the amount of GL partitioning to the condensed phase is dependent on more than just the LWC over the entire range of sulphate concentrations. The mechanism that is at work is still unknown, and the importance of this observation over the more limited sulphate concentration range of ambient aerosol is unclear. 


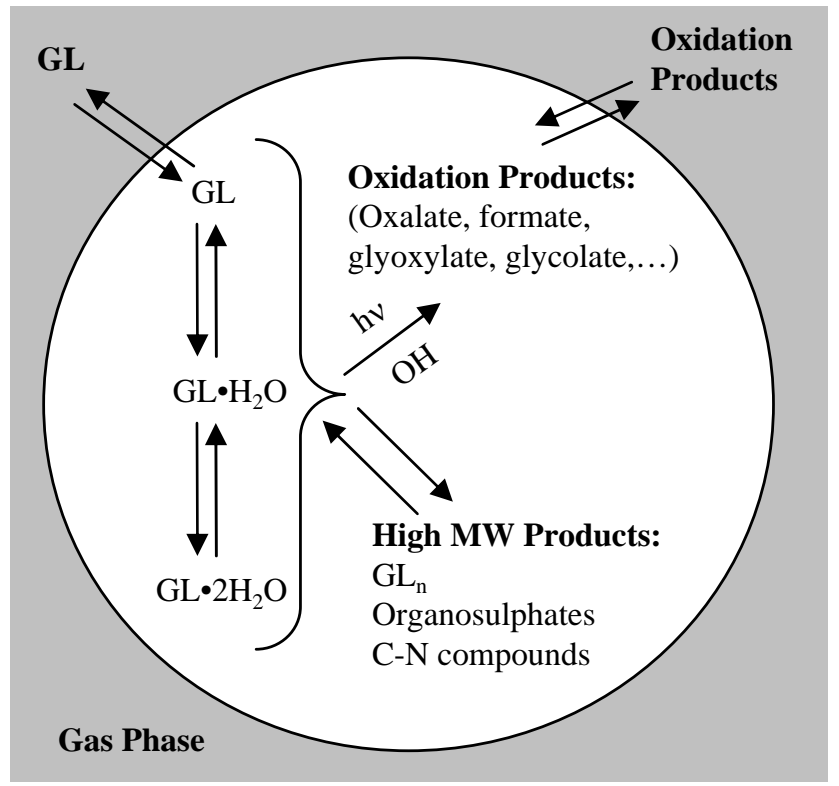

Fig. 1. Processes contributing to GL uptake on AS seed aerosol. $\mathrm{GL}=\mathrm{GL}$ monomer; $\mathrm{GL} \cdot \mathrm{H}_{2} \mathrm{O}=$ monohydrate; $\mathrm{GL} \cdot 2 \mathrm{H}_{2} \mathrm{O}=$ dihydrate; high molecular weight (MW) products include $\mathrm{GL}_{\mathrm{n}}$, organosulphates, and carbon-nitrogen containing compounds; oxidation products include oxalate, formate, glyoxylate, and glycolate and their oxidation products.

Bulk studies have also provided valuable insight into the aqueous GL system. Carlton et al. (2007) performed photochemical reactions of GL and hydrogen peroxide and demonstrated that SOA yield from GL depends on photochemical processing. Recent work by Nozière et al. (2009) showed that GL reacts to form high molecular weight compounds and postulated that the ammonium ion is a catalyst for condensed phase GL reactions such as oligomerization. In a different study, Shapiro et al. (2009) showed that light absorbing complexes were observed in solutions containing AS and GL but not in sodium sulphate or sodium chloride solutions, indicating that nitrogen is central to the formation of light absorbing complexes.

In light of these investigations, it is clear that particlephase chemistry plays a crucial role in the gas/particle partitioning of GL, though the processes controlling uptake are still not clear. In this study, we examine the uptake processes onto wet AS seed aerosol using a variety of instrumentation in dark conditions and in the presence of light. Figure 1 shows the major processes that could be contributing to GL uptake. The processes that have been identified by previous studies are:

1. GL-hydrate formation is fast and reversible (Schweitzer et al., 1998). Hydration equilibria up to $\mathrm{GL} \cdot 2 \mathrm{H}_{2} \mathrm{O}$, the dominant form of GL in dilute aqueous solutions, are included in $K_{\mathrm{H}, \mathrm{aq}}^{*}$ (Zhou and Mopper, 1990). Some

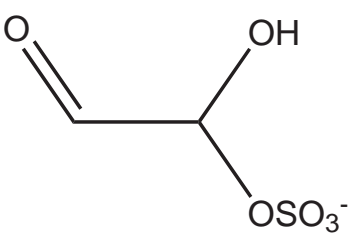

Glyoxal sulphate

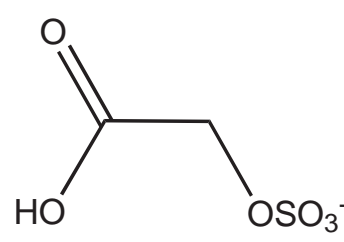

Glycolic acid sulphate
Fig. 2. Proposed structures for $m / z$ 155; glyoxal sulphate and glycolic acid sulphate.

studies have demonstrated correlation of organic growth with water content of aerosol (Volkamer et al., 2009), whereas others have shown growth at extremely low water content and noted that $\mathrm{GL} \cdot \mathrm{nH}_{2} \mathrm{O}$ concentrations appear to be independent of gas-phase GL concentrations (Corrigan et al., 2008).

2. Glyoxal oligomers $\left(\mathrm{GL}_{\mathrm{n}}\right)$ have been detected by timeof-flight and quadrupole AMS studies of aerosol growth from GL uptake in chamber experiments (Kroll et al., 2005; Liggio et al., 2005b); no definitive evidence for $\mathrm{GL}_{\mathrm{n}}$ in field samples has been found, likely due to analytical challenges. $\mathrm{GL}_{n}$ formation is reversible and slow (many minutes to hour timescales) in aqueous $\mathrm{GL} / \mathrm{H}_{2} \mathrm{O}$ solutions (Whipple, 1970; Fratzke and Reilly, 1986), and there are indications from a previous study that it is reversible in AS aerosol (Kroll et al., 2005).

3. The proposed GL sulphate $\left(\mathrm{C}_{2} \mathrm{H}_{3} \mathrm{SO}_{6}^{-}\right.$, Fig. 2) is of much interest as it has been detected via filter sampling methods in field samples (Surratt et al., 2007, 2008; Gómez-González et al., 2008) and in chamber studies of isoprene oxidation under intermediate- to high- $\mathrm{NO}_{\mathrm{x}}$ conditions (Surratt et al., 2008). The formation conditions for $\mathrm{C}_{2} \mathrm{H}_{3} \mathrm{SO}_{6}^{-}$as well as its contribution to $K_{\mathrm{H}, \mathrm{AS}}^{*}$ are unclear. Irreversible formation of $\mathrm{C}_{2} \mathrm{H}_{3} \mathrm{SO}_{6}^{-}$would not contribute to $K_{\mathrm{H}, \mathrm{AS}}^{*}$, however, reversible formation would have an effect on $K_{\mathrm{H}, \mathrm{AS}}^{*}$.

In this study we aim to investigate the processes contributing to overall GL uptake as well as which of these processes are effectively reversible, meaning reversible over aerosol lifetimes. These questions are important for evaluating applicability of laboratory studies to ambient conditions and net SOA yields from GL. If most GL uptake is effectively reversible, the organic aerosol will revolatilize at lower GL gas-phase concentrations upon transport away from GL sources or at night. Net SOA yields from a specific process will be higher if that process is irreversible. 
Table 1. Experimental conditions of dark experiments.

\begin{tabular}{|c|c|c|c|c|c|c|c|c|}
\hline & Seed $^{\mathrm{a}}$ & $\begin{array}{c}{[\mathrm{GL}]^{\mathrm{b}}} \\
\mathrm{ppb}_{\mathrm{v}}\end{array}$ & RH & $\begin{array}{r}\text { Temp } \\
\mathrm{K}\end{array}$ & $\mathrm{LWC}^{\mathrm{c}}$ & $\begin{array}{r}\text { Seed volume }{ }^{\mathrm{d}}, V \\
\mu \mathrm{m}^{3} / \mathrm{cm}^{3}\end{array}$ & $\begin{array}{r}\Delta V \\
\mu \mathrm{m}^{3} / \mathrm{cm}^{3}\end{array}$ & $\begin{array}{r}M_{\mathrm{GL}} \mathrm{e} \\
\mu \mathrm{g} / \mathrm{cm}^{3}\end{array}$ \\
\hline 1 & AS & 131 & $65 \%$ & 294 & $43 \%$ & 84.0 & 18.8 & 31.8 \\
\hline 2 & AS & 67 & $56 \%$ & 293 & $37 \%$ & 67.0 & 10.7 & 18.1 \\
\hline 3 & AS & 182 & $56 \%$ & 293 & $37 \%$ & 87.0 & 40.4 & 68.3 \\
\hline 4 & AS & $400^{\mathrm{f}}$ & $70 \%$ & 293 & $47 \%$ & 146.0 & 35.0 & 59.2 \\
\hline 5 & AS/SA & $400^{\mathrm{f}}$ & $70 \%$ & 293 & $49 \%$ & 94.0 & 104.0 & 176 \\
\hline 6 & $\mathrm{MgSO}_{4} / \mathrm{SA}$ & $400^{\mathrm{f}}$ & $70 \%$ & 293 & $67 \%$ & 149.0 & 114.0 & 193 \\
\hline 7 & $\mathrm{AS}$ & none & $70 \%$ & 294 & $47 \%$ & $77.0^{\mathrm{g}}$ & -- & -- \\
\hline
\end{tabular}

a $\mathrm{AS}=$ ammonium sulphate, $\mathrm{SA}=$ sulphuric acid

b $20 \%$ uncertainty on gas phase glyoxal values

c Calculated using ISORROPIA (Nenes et al., 1998)

$\mathrm{d}$ As measured by the DMA and corrected for wall loss

e Calculated assuming $\rho=1.69 \mathrm{~g} / \mathrm{cm}^{3}$

${ }^{\mathrm{f}}$ Estimated

g Not wall loss corrected

Table 2. Experimental conditions of irradiated experiments.

\begin{tabular}{|c|c|c|c|c|c|c|c|c|c|c|}
\hline & Seed $^{\mathrm{a}}$ & $\begin{array}{c}{[\mathrm{GL}]^{\mathrm{b}}} \\
\mathrm{ppb}_{\mathrm{v}}\end{array}$ & $\begin{array}{r}\mathrm{RH} \\
\text { Initial }\end{array}$ & $\begin{array}{r}\text { RH } \\
\text { Final }\end{array}$ & $\begin{array}{r}\text { Temp } \\
\text { Initial, } \mathrm{K}\end{array}$ & $\begin{array}{r}\text { Temp } \\
\text { Final, K }\end{array}$ & $\begin{array}{l}\text { LWC }^{c} \\
\text { Initial }\end{array}$ & $\begin{array}{r}\text { LWC }^{\mathrm{c}} \\
\text { Final }\end{array}$ & $\begin{array}{r}\text { Seed volume }{ }^{\mathrm{d}}, V \\
\mu \mathrm{m}^{3} / \mathrm{cm}^{3}\end{array}$ & $\begin{array}{r}\Delta V \\
\mu \mathrm{m}^{3} / \mathrm{cm}^{3}\end{array}$ \\
\hline 8 & AS & 86.2 & $66.0 \%$ & $42.6 \%$ & 293.0 & 299.4 & $43.7 \%$ & $28.4 \%$ & 81.0 & -14.0 \\
\hline 9 & $\mathrm{AS} / \mathrm{Fe}$ & 128 & $64.6 \%$ & $42.5 \%$ & 292.8 & 299.3 & $43.0 \%$ & $28.4 \%$ & 78.9 & -13.5 \\
\hline 10 & AS & 127 & $55.7 \%$ & $37.9 \%$ & 292.8 & 299.4 & $36.7 \%$ & $25.2 \%$ & 87.0 & -12.0 \\
\hline 11 & AS & none & $59.6 \%$ & $54.7 \%$ & 293.1 & 294.4 & $39.4 \%$ & $36.0 \%$ & $62.3^{\mathrm{e}}$ & -- \\
\hline
\end{tabular}

a $\mathrm{AS}=$ ammonium sulphate, $\mathrm{Fe}=\mathrm{Fe}_{2}\left(\mathrm{SO}_{4}\right)_{3}$

b $20 \%$ uncertainty on gas phase glyoxal values

c Calculated using ISORROPIA (Nenes et al., 1998)

d As measured by the DMA and corrected for wall loss

e Not wall loss corrected

\section{Experimental procedures}

Experiments were performed in Caltech's indoor, dual $28 \mathrm{~m}^{3}$ Teflon environmental chambers (Cocker et al., 2001; Keywood et al., 2004). The experimental conditions are summarized in Tables 1 and 2. Each chamber has a dedicated Differential Mobility Analyzer (DMA, TSI model 3081) coupled with a condensation nucleus counter (TSI model 3760) for measuring aerosol size distribution, and number and volume concentration. Temperature, relative humidity ( $\mathrm{RH})$, $\mathrm{O}_{3}, \mathrm{NO}$, and $\mathrm{NO}_{\mathrm{x}}$ were continuously monitored. AS seed particles were generated by atomization of a $0.015 \mathrm{M}$ aqueous AS solution using a constant rate atomizer. Acidic seed particles were generated by atomization of a $0.015 \mathrm{M}$ aqueous AS solution containing $0.015 \mathrm{M}$ sulphuric acid. GL was prepared by heating a mixture of solid GL trimer dihydrate (Sigma, minimum 97\%) and phosphorus pentoxide $\left(\mathrm{P}_{2} \mathrm{O}_{5}\right)$ to $\sim 160^{\circ} \mathrm{C}$ under vacuum. The monomer was collected in an $\mathrm{LN}_{2}$ trap as a yellow solid and stored overnight at $-20^{\circ} \mathrm{C}$. Before each experiment, the frozen monomer was allowed to vaporize into a $500 \mathrm{~mL}$ glass bulb and introduced into the chamber using a gentle air stream. The chamber was kept at $\sim 60 \% \mathrm{RH}$. The concentration of an inert tracer, cyclohexane, was monitored using a gas-chromatograph with flame ionization detector (GC-FID, Agilent 6890N).

Dark experiments typically began by introducing gasphase GL into a dark chamber and allowing the concentration to equilibrate over $\sim 10 \mathrm{~h}$. Approximately $160 \mathrm{ppb}_{\mathrm{v}}$ (partper-billion by volume) of cyclohexane was also added as a tracer for dilution. Once the gas-phase GL concentration reached a steady state, AS seed was introduced and the resulting organic growth was monitored by both the DMA and a high resolution time-of-flight AMS (HR-ToF-AMS, hereby referred to as AMS). After organic growth levelled off, the 
chamber air mass was diluted with clean hydrocarbon-free air to investigate the reversibility of uptake. The amount of dilution was calculated by monitoring the cyclohexane concentration with the GC-FID. In some experiments, AS seed was added first and then GL, though the results are the same.

Experiments with irradiation began similarly to dark experiments but when the addition of GL or AS seed was complete, the chamber lights were turned on. No external $\mathrm{OH}$ or $\mathrm{NO}_{\mathrm{x}}$ source was added, and no dilution was performed in irradiated experiments.

Two blank experiments (Exp. 7 and 11) were conducted in which wet AS seed was atomized into a humid chamber without GL present. A negligible organic signal was measured in the absence of radiation, most likely due to background organics from the chamber walls. Under irradiation, miniscule organic growth was observed.

\subsection{Teflon filter collection and offline chemical analysis}

Teflon filters (PALL Life Sciences, $47 \mathrm{~mm}$ diameter, $1.0 \mu \mathrm{m}$ pore size, teflo membrane) were collected from each experiment for offline chemical analysis. Filter sampling was initiated when the aerosol volume reached its maximum (constant) value, as determined by the DMA. Depending on the total volume concentration of aerosol in the chamber, the duration of filter sampling was 3.6-4.1 h, which resulted in $\sim 5.1-5.8 \mathrm{~m}^{3}$ of total chamber air sampled. Collected filters were extracted in high-purity methanol, dried, and then reconstituted with $250 \mu \mathrm{L}$ of a $1: 1(\mathrm{v} / \mathrm{v})$ solvent mixture of $0.1 \%$ acetic acid in water and $0.1 \%$ acetic acid in methanol (Surratt et al., 2008). All filter extracts were analyzed by a Waters ACQUITY ultra performance liquid chromatography (UPLC) system, coupled to a Waters LCT Premier XT time-of-flight mass spectrometer (TOFMS) equipped with an electrospray ionization (ESI) source. The ESI source was operated in both negative $(-)$ and positive $(+)$ ion mode; acidic GL SOA components were detected in the negative ion mode, whereas $\mathrm{C}-\mathrm{N}$ compounds (e.g. imidazoles) were detected in the positive ion mode. All other operating conditions for this technique have been fully described elsewhere (Surratt et al., 2008).

Blank Teflon filters were extracted and treated in the same manner as the samples; none of the SOA products detected on the filter samples collected from the GL chamber experiments were observed in these blanks, indicating that these SOA components were not introduced during sample storage and/or preparation. Furthermore, to ensure that the SOA components observed were not an artefact formed from the collection of gaseous GL onto filter media, a blank filter was collected under dark conditions from the chamber containing a well mixed concentration of GL $\left(\sim 2 \mathrm{ppm}_{\mathrm{V}}\right)$ and analyzed with UPLC/ESI-HR-TOFMS. This blank was sampled for the same duration as a sample filter. No SOA components characterized in the present study or significant contaminants were observed, consistent with the lack of observed aerosol growth in the absence of light and AS seed aerosol. All filters used for UPLC/ESI-HR-TOFMS analysis were examined within 1-2 days of the filter extraction/sample preparation. Following their initial analysis, sample extract solutions were stored at $-20^{\circ} \mathrm{C}$. Selected samples were reanalyzed a month after initial extraction and showed no signs of degradation.

\subsection{Aerodyne aerosol mass spectrometer}

Real-time particle mass spectra were collected continuously by the AMS, which is described in detail elsewhere (DeCarlo, 2006; Canagaratna et al., 2007, and references therein). The AMS switched once every minute between a high resolution "W-mode" and a lower resolution, higher sensitivity "V-mode". The "V-mode" data were analyzed using a fragmentation table to separate out sulphate, ammonium, and organic spectra and to time-trace specific mass-tocharge ratios. "W-mode" data were analyzed using a separate high-resolution spectra toolbox known as PIKA to determine the chemical formulas contributing to distinct massto-charge ratios (DeCarlo, 2006). Since GL easily fragments to produce $\mathrm{CH}_{2} \mathrm{O}^{+}$, the fragmentation table was corrected so that the organic signal at $\mathrm{m} / \mathrm{z}, 30$ was equal to its total signal minus the contribution from air. The nitrate contribution was changed to approximately 1.3 times the nitrate signal at $m / z 46$ as this was the 30/46 ratio during ammonium nitrate calibrations.

To determine elemental ratios, the computational toolbox known as Analytical Procedure for Elemental Separation (APES) was used. This toolbox applies the analysis procedure described in Aiken et al. (2007) to the high-resolution "W-mode data". The particle-phase signal of $\mathrm{CO}^{+}$and the organic contribution to $\mathrm{H}_{\mathrm{x}} \mathrm{O}^{+}$ions were estimated as described in Aiken et al. (2008).

\subsection{Madison laser-induced phosphorescence instru- ment}

Gas-phase GL was detected with high specificity via LaserInduced Phosphorescence (LIP) using the Madison LIP Instrument described in Huisman et al. (2008). This instrument utilizes a White-type multipass cell in a 2-pass configuration with gated photon counting and is highly sensitive, permitting specific, direct, in situ measurement of GL with a oneminute limit of detection $(3 \sigma)$ of $6 \mathrm{ppt}_{\mathrm{v}}$ (part-per-trillion by volume) per minute in a 32-pass configuration.

\section{Results}

\subsection{Glyoxal uptake in the absence of light}

For a typical experiment, gas-phase GL was present in the chamber and equilibrated with the chamber walls prior to the 
Table 3. GL fragments observed via AMS and suggested structures from which the fragments are formed.

\begin{tabular}{|c|c|c|}
\hline $\mathrm{m} / \mathrm{z}$ & Fragment Formula & Suggested Structure \\
\hline 29 & $\mathrm{CHO}^{+}$ & \\
\hline 58 & $\mathrm{C}_{2} \mathrm{H}_{2} \mathrm{O}_{2}^{+}$ & \\
\hline 77 & $\mathrm{C}_{2} \mathrm{H}_{5} \mathrm{O}_{3}^{+}$ & \\
\hline 88 & $\mathrm{C}_{3} \mathrm{H}_{4} \mathrm{O}_{3}^{+}$ & \\
\hline 105 & $\mathrm{C}_{3} \mathrm{H}_{5} \mathrm{O}_{4}^{+}$ & \\
\hline 117 & $\mathrm{C}_{4} \mathrm{H}_{5} \mathrm{O}_{4}^{+}$ & \\
\hline 135 & $\mathrm{C}_{4} \mathrm{H}_{7} \mathrm{O}_{5}^{+}$ & \\
\hline 145 & $\mathrm{C}_{5} \mathrm{H}_{5} \mathrm{O}_{5}^{+}$ & \\
\hline 175 & $\mathrm{C}_{6} \mathrm{H}_{7} \mathrm{O}_{6}^{+}$ & \\
\hline
\end{tabular}

introduction of AS seed particles. Organic growth began immediately upon particle addition, and reached a maximum after approximately $10 \mathrm{~h}$; over this time period, sulphate and ammonium decreased due to particle wall losses. A representative unit-mass AMS spectrum is shown in Fig. 3. The fragments of interest to this study are summarized in Tables 3 and 4. The most significant fragments are $m / z 44,58,68,135$, 145 , and 175. The observed fragments are in general accord with those observed by Liggio et al. (2005a), though certain masses such as $m / z, 192$ and 193 have lower signals in this study. Proposed precursor structures for the fragment masses marked in Fig. 3 are listed in Table 3. The fragment chemical formulae are unequivocally confirmed by the high-resolution spectra obtained in "W-mode", verifying many of the assignments made by Liggio et al. (2005a). Masses listed in Table 3 which are larger than or equal to $m / z 77$ represent ion fragments of oligomers; as an example, the high-resolution peak for $m / z, 135$ is shown in Fig. 4a. In the high resolution spectra, the only fragment ion found to contain both sulphur and carbon is $m / z 79\left(\mathrm{CH}_{3} \mathrm{SO}_{2}^{+}\right)$; however, the signal intensity is similar to that in the blank experiment (Exp. 7). Filter sample analysis did not detect any organosulphates under dark conditions in neutral (Exp. 4) or acidic seed (Fig. 5c, Exp. 5 and 6 ), as can be seen in the comparison between experiments carried out under irradiated conditions (Fig. 5a, Exp. 10) and experiments performed in the dark (Fig. 5b, Exp. 3).

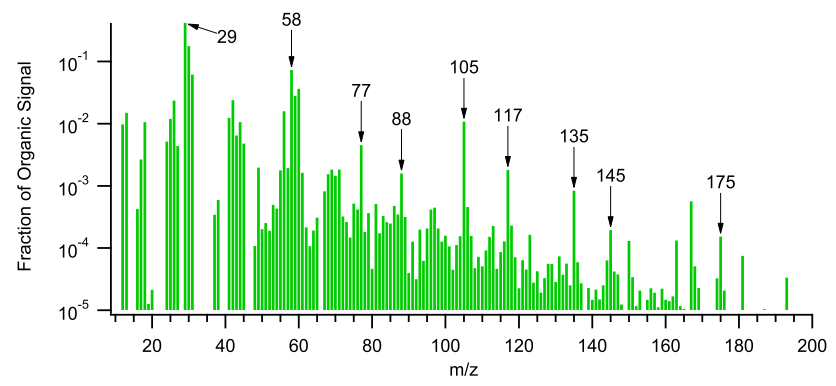

Fig. 3. Representative unit-mass AMS spectrum. Distinct GL and GL oligomer marker peaks are shown. The compound from which each fragment was formed is listed in Table 3.
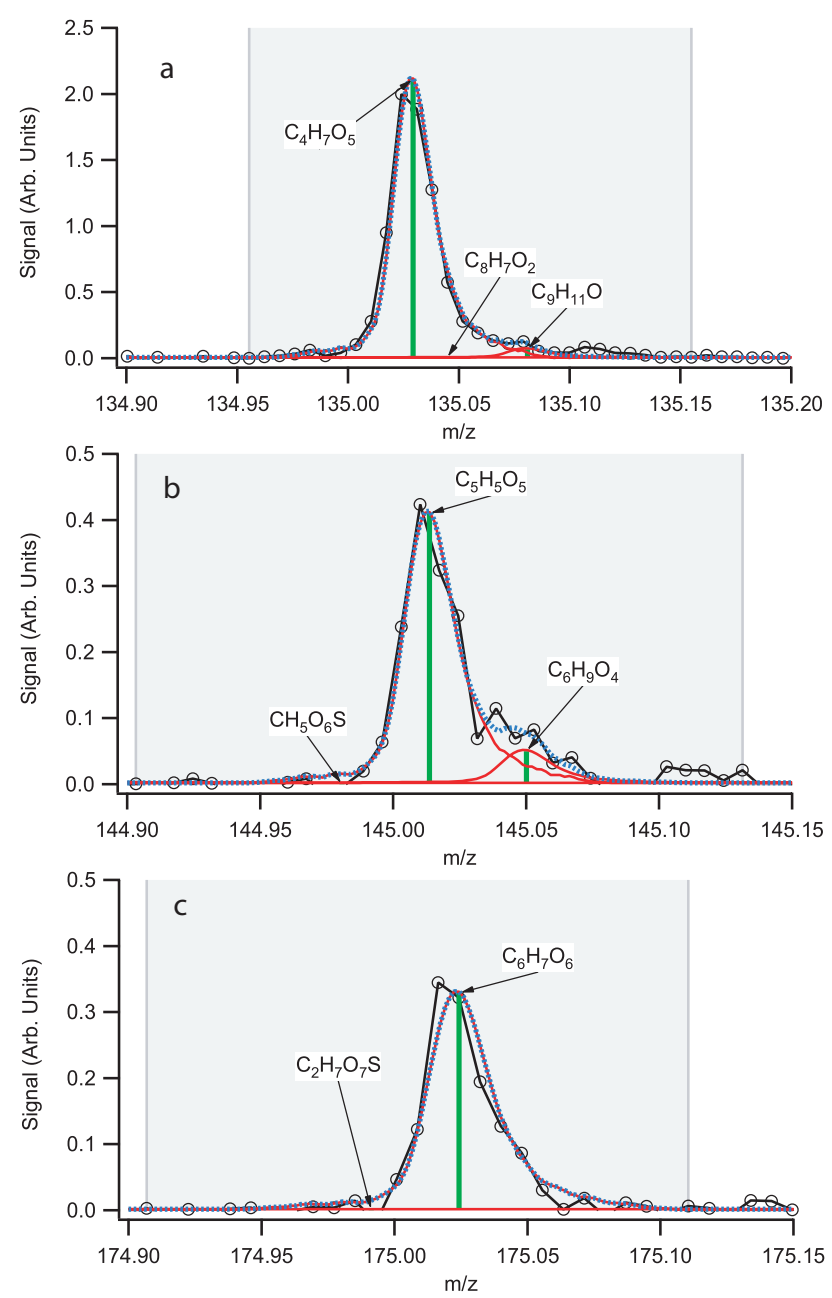

Fig. 4. High-resolution ("W-mode") AMS peaks allow unequivocal assignment of $\mathrm{C}_{4} \mathrm{H}_{7} \mathrm{O}_{5}^{+}$formula to the $m / z, 135, \mathrm{C}_{5} \mathrm{H}_{5} \mathrm{O}_{5}^{+}$formula to the $m / z, 145$, and $\mathrm{C}_{6} \mathrm{H}_{7} \mathrm{O}_{6}^{+}$formula to the $m / z, 175$ fragment ions. 


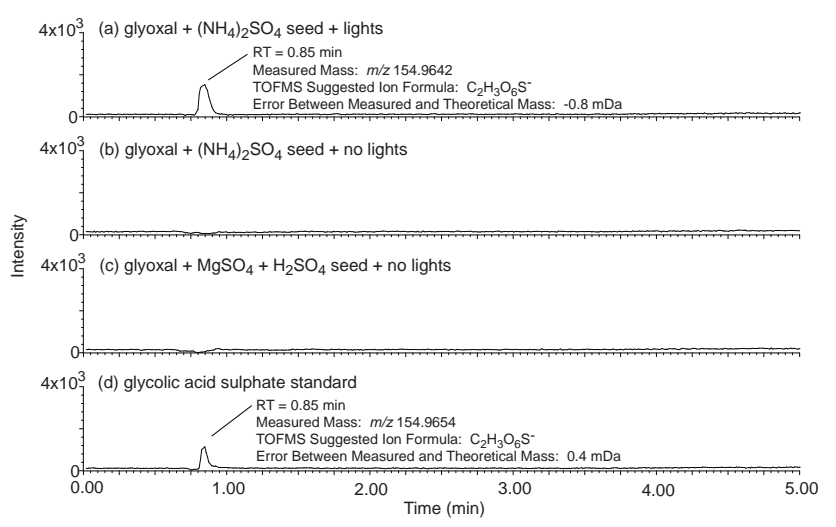

Fig. 5. UPLC/ESI-TOFMS extracted ion chromatograms (EICs) of $\mathrm{m} / \mathrm{z}, 155$ for selected GL experiments. The comparison of these EICs reveals that glycolic acid sulphate only forms under irradiated conditions when using AS seed aerosol. Comparison of the retention time (RT) and mass $(\mathrm{m} / \mathrm{z})$ of the compound detected in panel (a) and the glycolic acid sulphate standard, (d), unequivocally shows that glycolic acid sulphate is being formed in the presence of light, but not in neutral, (b), or acidic, (c), dark experiments.

After particle growth has stopped, the chamber was diluted with clean air (Exp. 1 and 3) to investigate the reversibility of GL uptake. Upon dilution, the concentrations of tracer, gas-phase GL, and particle-phase organic, sulphate, and ammonium decreased. To remove the effect of the decrease in overall particle volume due to wall loss and to dilution, the organic and several marker signals are normalized to sulphate. This normalized signal is proportional to the condensed phase concentration of each species. The normalized organic signal and GL markers at $m / z 58$ and $m / z, 105$ decrease after dilution by $15-25 \%$ and $18-30 \%$, respectively. The gas-phase GL concentration decreased by $25-40 \%$ of the initial concentration and the overall organic signal decreased relative to the tracer signal. Figure 6 shows this for a typical dilution experiment (Exp. 3).

Several fragments were observed by the AMS to have different temporal characteristics (and thus uptake kinetics) than the total organic or $\mathrm{GL}_{\mathrm{n}}$ signal. Relatively strong signals occurred at $m / z 41,68,69$, and 70 . Weaker signals, approximately 5-10 times lower in magnitude, were also detected at other masses, the largest fragment occurring at $\mathrm{m} / z 96$. The signal at $m / z 68$ increased immediately upon seed injection and grew steadily, even after no further change in total organic growth was observable within the uncertainty of that measurement. Furthermore, during dilution, the signal continued to increase when normalized to the sulphate signal. These compounds contribute only $\sim 0.5 \%$ of total organic mass measured by the AMS, but the sensitivity for these compounds or the $\mathrm{GL}_{n}$ has not been calibrated, and it is unlikely such a calibration can be achieved for the oligomers. Dilution has very little effect on the relative growth of $m / z 68$, implying that the reactions are irreversible with respect to the

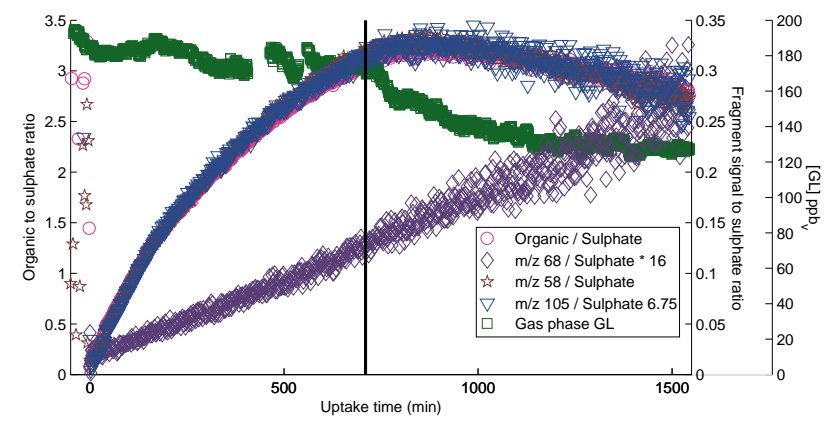

Fig. 6. The time traces of total organic, $m / z 58,105$, and 68 fragment ions normalized by the sulphate ion signal along with gas phase GL concentrations for a dilution experiment (Exp. 3). Dilution begins at the black vertical line. Upon dilution, the normalized organic and GL $(\mathrm{m} / \mathrm{z}, 58$ and 105$)$ marker signals decrease by $30 \%$, and $17 \%$, respectively, which is less than the $25 \%$ reduction in gasphase GL concentrations. However, the system has clearly not equilibrated and thus further loss of particle-phase GL is expected. In contrast to the reversible behaviour of total organic and GL and GL oligomer growth, the growth of the $m / z 68$ (imidazole) marker has markedly different characteristics, indicating irreversible uptake.

lifetime of chamber aerosol. The high-resolution spectra obtained with the AMS in "W-mode" show unequivocally that these fragments originate from compounds containing carbon and nitrogen, as discussed below. Filter sample analysis also showed the presence of several nitrogen containing species in positive mode, including a species with $m / z 97$.

\subsection{Glyoxal uptake in the presence of light}

The AMS spectra in irradiated experiments initially resembled those of dark uptake experiments, with many of the same marker fragments prominent, but then changed quickly. As under non-irradiated conditions, gaseous GL partitioned immediately to the AS seed under UV light. The organic signal increased quickly upon addition of AS aerosol, but began to decrease soon after irradiation began. Upon reaching a maximum, the GL marker signal decayed faster than wall loss and the maximum is reached earlier than in the experiments under dark conditions. No dilution was performed in the irradiated experiments. The fractional contribution of $m / z 44$ and $m / z 68$ increased upon irradiation (Fig. 7). The irradiation resulted in a temperature increase of $\sim 5^{\circ} \mathrm{C}$ and a drop in relative humidity (see Table 2 ). As a result, the liquid water content (LWC) was lowered and the total aerosol volume decreased, which made it impossible to determine the mass of GL taken up into the aerosol from the DMA data. The fragment with $m / z, 44$ can be confidently assigned as $\mathrm{CO}_{2}^{+}$, and in AMS spectra is considered an indicator of the oxidation state of organic aerosol. Its increase in irradiated experiments points to the fact that the amount of oxidized organic species is increasing in these experiments. 


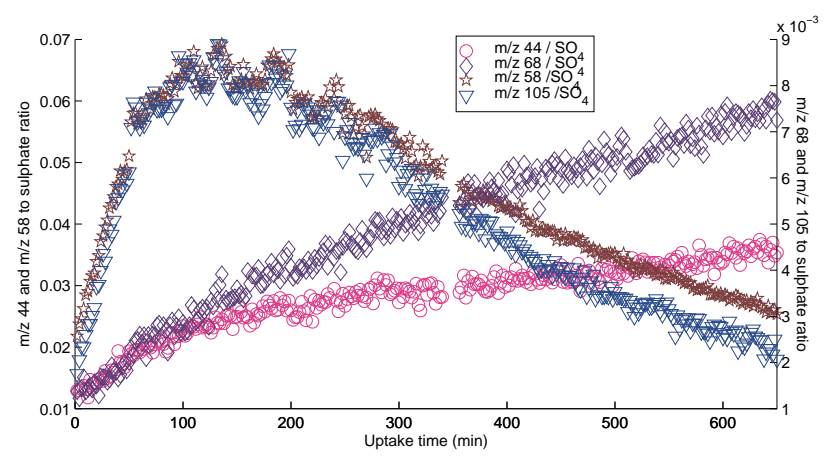

Fig. 7. The sulphate normalized GL and GL oligomer marker signals $m / z, 58$ and 105 increase rapidly on introduction of seed aerosol under irradiated conditions, but decrease rapidly without any dilution taking place, which is in marked difference to the dark experiments. The $m / z 44$, and in particular, 68 marker signals increase steadily during these experiments, indicating oxidation of the organic fraction of the aerosol and continued imidazole formation.

In agreement with this, numerous highly oxidized organic species were detected via the UPLC/ESI-HR-TOFMS analysis, including glyoxylic, glycolic, and formic acids. Filter sample analysis also showed the presence of a sulphur containing compound with $m / z 155$. No $\mathrm{OH}$ source was added in these experiments but a small amount of $\mathrm{OH}$ is potentially being produced via photolysis of GL, resulting in formation of the carboxylic acids. In one experiment, $\mathrm{Fe}$ was added to the seed (Exp. 9). The results closely resembled those of the other irradiated experiments (Exp. 8 and 10). Although carboxylic acids are formed, the $\mathrm{O}: \mathrm{C}$ ratio of the organic fraction of the aerosol is not increasing but rather decreasing. In contrast the $\mathrm{H}: \mathrm{C}$ and $\mathrm{N}: \mathrm{C}$ ratios both increase in these experiments. The ammonium fraction of the aerosol is excluded in the calculation of $\mathrm{N}: \mathrm{C}$ ratio.

\section{Discussion}

\subsection{Organosulphate formation}

The fragment ions $m / z 145$ and 175 , which were previously assigned the formulas $\mathrm{CH}_{5} \mathrm{O}_{6} \mathrm{~S}^{+}$and $\mathrm{C}_{2} \mathrm{H}_{7} \mathrm{O}_{7} \mathrm{~S}^{+}$, respectively by Liggio et al. (2005a), were unequivocally determined to be $\mathrm{C}_{5} \mathrm{H}_{5} \mathrm{O}_{5}^{+}$and $\mathrm{C}_{6} \mathrm{H}_{7} \mathrm{O}_{6}^{+}$, respectively (Fig. 4a and b) with the AMS in "W-mode". The detection of these fragments demonstrates the existence of trimers or larger $\mathrm{GL}_{\mathrm{n}}$ in the aerosol. Liggio et al. (2005a) suggested that these fragments correspond to fragmentation products of GL sulphates formed from a proposed aqueous reaction of sulphate or bisulphate with GL. If this proposed mechanism were correct, it would be the only evidence prior to the work presented here for the formation of GL sulphates in chamber aerosol resulting from GL uptake. The current study is in the unique position to unambiguously determine the chemi- cal formulas of both fragment ions due to the employment of the high-resolution "W-mode", which is not possible with a quadrupole AMS. No sulphate esters were detected by the UPLC/ESI-HR-TOFMS analysis of filter samples in nonirradiated conditions with neutral or acidic seed (Fig. 5b and $5 \mathrm{c})$. This evidence suggests that GL sulphate does not form in dark GL uptake experiments with AS seed.

Our results do not rule out that sulphates were formed in the study by Liggio et al. (2005b), and our irradiated experiments clearly demonstrate that organosulphates can form. Figure 5a shows that $m / z 155$, which corresponds to glycolic acid sulphate $\left(\mathrm{C}_{2} \mathrm{H}_{3} \mathrm{SO}_{6}^{-}\right.$, see below), is measured in filter samples obtained during irradiated experiments (Exp. 8 and 10). The AMS did not detect this sulphate, most likely due to a high degree of fragmentation. The same organosulphate (as judged by elution time and formula) $\mathrm{C}_{2} \mathrm{H}_{3} \mathrm{SO}_{6}^{-}$has previously been detected in filter samples from isoprene photooxidation experiments conducted in the Caltech chamber (Surratt et al., 2008) under intermediate- and high- $\mathrm{NO}_{\mathrm{x}}$ conditions, which favour GL production, but only with acidic seed. Ambient organic aerosol collected from K-puszta, Hungary (Gómez-González et al., 2008) and from the southeastern US (Surratt et al., 2008) has also been found to contain this $\mathrm{C}_{2} \mathrm{H}_{3} \mathrm{SO}_{6}^{-}$organosulphate. In the previous work this sulphate was proposed to be GL sulphate. In all of these studies the filter extraction was performed in methanol. As sulphate is a better leaving group than methoxy, it appeared likely that the initially proposed GL sulphate would not be observed with the methanol extraction method, as it should dissociate. Thus, isomers of $\mathrm{C}_{2} \mathrm{H}_{3} \mathrm{SO}_{6}^{-}$were investigated and glycolic acid sulphate was chosen as a likely candidate since this sulphate should be more stable in methanol and as a different glycolic acid ester was proposed as one of the products of the light induced experiments in the work presented here, which suggests that a pathway for glycolic acid production exists. We subsequently synthesized the glycolic acid sulphate and verified that the mass and elution time of the standard and the $\mathrm{C}_{2} \mathrm{H}_{3} \mathrm{SO}_{6}^{-}$sulphate observed in this and previous studies were identical using UPLC/ESI-HR-TOFMS (Fig. 5d). This analysis shows that previous assignments of glyoxal sulphate that were obtained via filter extraction involving methanol or related solvents, such as in the chamber and ambient aerosol studies mentioned above, should be revisited as carbonyl sulphates are not stable under these conditions. However, this does not rule out the existence of carbonyl sulphates under the conditions present in aerosol.

This is the first report of glycolic acid sulphate measured in chamber filter samples of GL uptake, and one of the few organosulphates to be positively identified in ambient aerosol. Acid catalysis has been traditionally been implicated in the formation of organosulphates. However, this study shows no sulphate formation under acidic conditions in the absence of light (Exp. 5 and 6) and recent studies have questioned this pathway for lower tropospheric conditions and instead proposed an epoxide pathway (Minerath et al., 2008; 
Table 4. Fragments containing both carbon and nitrogen observed and suggested chemical formulas. The masses detected by UPLC/(+)ESI-TOFMS were detected in the protonated form.

\begin{tabular}{lll}
\hline & $m / z$ & Fragment formula \\
\hline Strong ions & 41 & $\mathrm{C}_{2} \mathrm{H}_{3} \mathrm{~N}^{+}$ \\
& 68 & $\mathrm{C}_{3} \mathrm{H}_{4} \mathrm{~N}_{2}^{+}$ \\
& 69 & $\mathrm{C}_{3} \mathrm{H}_{3} \mathrm{NO}^{+}$ \\
& 70 & $\mathrm{C}_{3} \mathrm{H}_{4} \mathrm{NO}^{+}$ \\
Weak ions & 46 & $\mathrm{CH}_{4} \mathrm{NO}^{+}$ \\
& 52 & $\mathrm{C}_{3} \mathrm{H}_{2} \mathrm{~N}^{+}$ \\
& 53 & $\mathrm{C}_{3} \mathrm{H}_{3} \mathrm{~N}^{+}$ \\
& 57 & $\mathrm{C}_{2} \mathrm{H}_{3} \mathrm{NO}^{+}$ \\
& 68 & $\mathrm{C}_{3} \mathrm{H}_{2} \mathrm{NO}^{+}$ \\
& 96 & $\mathrm{C}_{4} \mathrm{H}_{4} \mathrm{~N}_{2} \mathrm{O}^{+}$ \\
& 97 & $\mathrm{C}_{4} \mathrm{H}_{5} \mathrm{~N}_{2} \mathrm{O}^{+}$ \\
& 115 & $\mathrm{C}_{4} \mathrm{H}_{7} \mathrm{~N}_{2} \mathrm{O}_{2}^{+}$ \\
& 129 & $\mathrm{C}_{5} \mathrm{H}_{9} \mathrm{~N}_{2} \mathrm{O}_{2}^{+}$ \\
& 159 & $\mathrm{C}_{6} \mathrm{H}_{11} \mathrm{~N}_{2} \mathrm{O}_{3}^{+}$ \\
& 173 & $\mathrm{C}_{7} \mathrm{H}_{13} \mathrm{~N}_{2} \mathrm{O}_{3}^{+}$ \\
& 184 & $\mathrm{C}_{7} \mathrm{H}_{10} \mathrm{~N}_{3} \mathrm{O}_{3}^{+}$ \\
\hline
\end{tabular}

Minerath and Elrod, 2009). In contrast, the glycolic acid sulphate formation observed in this work requires a light induced pathway as it is only observed in the presence of light (Exp. 8 and 10), even in neutral seed aerosol. Although the identification of $\mathrm{C}_{2} \mathrm{H}_{3} \mathrm{SO}_{6}^{-}$as glycolic acid sulphate reconciles the expected chemical stability to methanol extraction, it is unclear how glycolic acid or its sulphate are formed, although the increasing $m / z 44$ marker shows that there is active oxidative chemistry occurring in the presence of UV light. However, glycolic acid is not an oxidation product of GL but rather a disproportionation product. We are currently investigating the pathway for glycolic acid sulphate formation, which is unlikely to involve an epoxide.

\subsection{Carbon-nitrogen containing compound formation}

Although no significant AMS fragments containing both sulphur and carbon are found, several fragments in the highresolution spectra are found to contain nitrogen together with carbon, hydrogen and occasionally oxygen (Table 4). In addition, filter samples analyzed with UPLC/ESI-HR-TOFMS in positive mode showed compounds containing carbon and nitrogen (C-N compounds), listed in Table 4. The identification of the species corresponding to the chemical formulae listed in Table 4 is ongoing but we have achieved a positive identification of three masses in the AMS spectra; the strong signals at $m / z 41\left(\mathrm{C}_{2} \mathrm{H}_{3} \mathrm{~N}\right)$ and $68\left(\mathrm{C}_{3} \mathrm{H}_{4} \mathrm{~N}_{2}\right.$, Fig. 8a), and a weaker signal at $m / z, 96\left(\mathrm{C}_{4} \mathrm{H}_{4} \mathrm{~N}_{2} \mathrm{O}\right.$, Fig. 8b). The carrier of $m / z, 97$ from the filter samples also had the formula $\mathrm{C}_{4} \mathrm{H}_{4} \mathrm{~N}_{2} \mathrm{O}$ (after the subtraction of a proton) in high-resolution positive
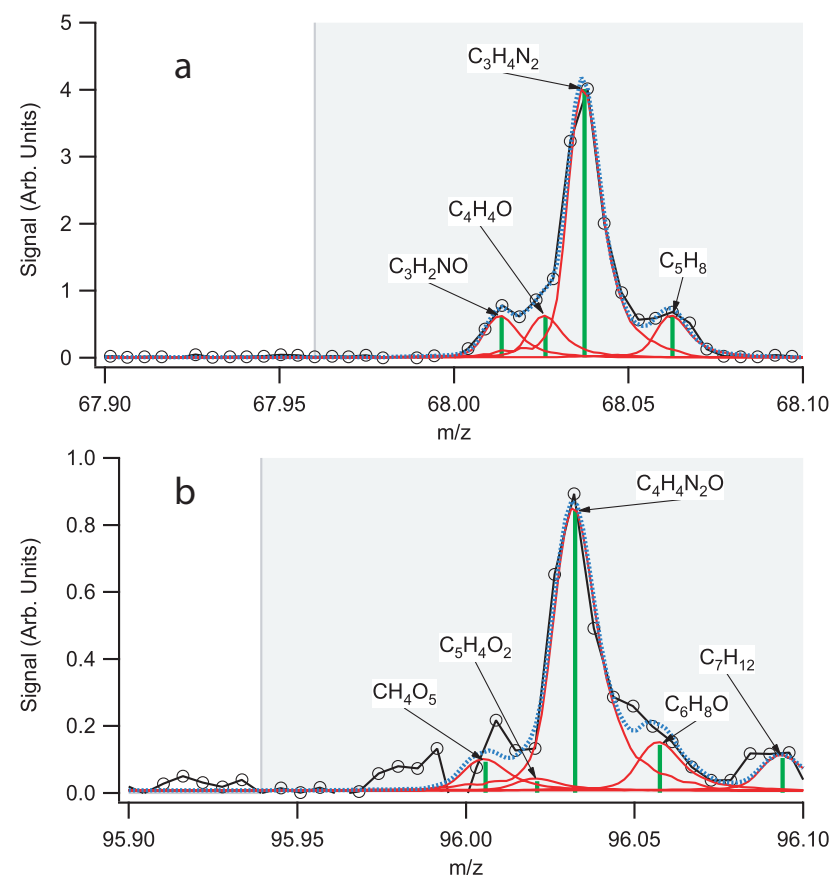

Fig. 8. High-resolution (W-mode) AMS peaks allow unequivocal assignment of a $\mathrm{C}_{3} \mathrm{H}_{4} \mathrm{~N}_{2}^{+}$formula to the $m / z 68, \mathrm{C}_{4} \mathrm{H}_{4} \mathrm{~N}_{2} \mathrm{O}^{+}$formula to the $m / z, 96$ fragment ions.

mode ESI and had the same elution time as a standard of 1H-imidazole-2-carboxaldehyde (Sigma-Aldrich). The AMS fragments are also consistent with 1H-imidazole-2carboxaldehyde. The high-resolution masses observed with UPLC/ESI-HR-TOFMS and the AMS, the AMS fragmentation pattern and the observed elution time provide strong support for the assignment of the carrier of this signal to 1H-imidazole-2-carboxaldehyde. In further support of this finding, the general Debus mechanism for imidazole formation (see following paragraph) predicts the formation of $1 \mathrm{H}-$ imidazole-2-carboxaldehyde as shown in Fig. 9. Other C-N containing products were observed, but have not been positively identified. The production of a very stable aromatic compound such as an imidazole may be the thermodynamic driving force behind this reaction and explains why carbonnitrogen containing fragments are observed in the AMS. This is in contrast to the case of organic nitrates, which fragment easily via loss of the nitrogen moiety.

Since no $\mathrm{NO}_{\mathrm{x}}$ was present or added to the chamber before GL addition, the only source of labile nitrogen is ammonium from AS. Therefore, the C-N ions likely arise from fragmentation of products of a reaction between GL and ammonium. Although the ammonium ion is not a nucleophile and is not expected to react with GL, there will be a non-negligible concentration of ammonia in equilibrium with ammonium at the $\mathrm{pH}$ found in AS aerosol. The reaction of GL and ammonia is an established organic reaction for synthesis of imidazole and was described in 1858 (Debus, 1858). In view of recent 


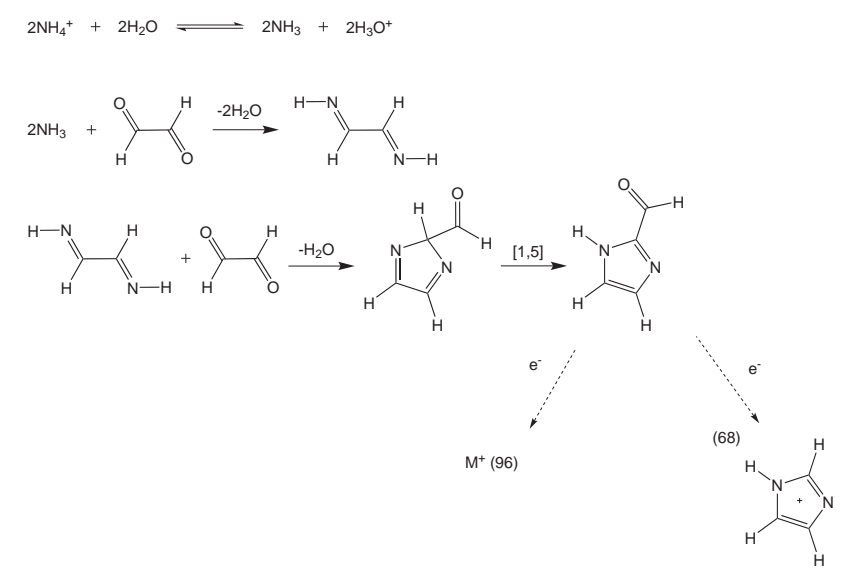

Fig. 9. Proposed formation mechanism of $1 \mathrm{H}$-imidazole-2carboxaldehyde and observed $m / z 68$ and 96 fragment ion.

literature describing the observation of light absorbing complexes and higher molecular weight compounds from reaction of bulk solutions containing AS and GL (Nozière et al., 2009; Shapiro et al., 2009), it is interesting to note the observations by Debus (1858). Debus (1858) describes formation of a brown solution as well as two colourless products; imidazole $\left(\mathrm{C}_{3} \mathrm{H}_{4} \mathrm{~N}_{2}\right)$ and $\mathrm{C}_{6} \mathrm{H}_{6} \mathrm{~N}_{4}$, most likely 2,2'-bi-1Himidazole, which is available commercially as a coloured compound. Thus the reaction of GL with ammonia has a long history. In addition to reaction with ammonia, the reaction of GL with AS in bulk solution is well established. In fact, a method for reaction of GL with formaldehyde and AS in bulk aqueous solution with $69 \%$ yield has been published and patented (Schulze, 1973). The author states the yield of imidazole is surprisingly high, which could be a result of catalytic activity by ammonium (proposed recently by Nozière et al., 2009) in addition to being a reactant, although this is complicated by the pronounced effect of anions on GL (Ip et al., 2009). A similar method for the production of 2,2'-bi-1H-imidazole in bulk aqueous solution via reaction of GL in AS with 43-54\% yield has also been published and patented (Cho et al., 2003). Thus, reaction of GL with AS in bulk solutions to form coloured compounds has a well established history. Other studies have addressed the effect of added gas-phase ammonia (Na et al., 2006, 2007), organic amines (Angelino et al., 2001; Murphy et al., 2007; Silva et al., 2008), and amino acids (De Haan et al., 2009) on SOA formation as well as bulk phase reactions between AS and GL (Nozière et al., 2009; Shapiro et al., 2009) and amino acids and GL (De Haan et al., 2009), but to the authors' knowledge, imidazole compounds have not been previously detected in AS seed aerosol chamber studies. The mass spectrum published by Liggio et al. (2005a) does not show a peak at $m / z 68$. However, subsequent to the initial publication of our work, De Haan et al. (2009) identified substituted imidazole compounds formed from the reaction of GL and amino acids in both the bulk phase and in solid phase aerosols. We report the first observation of the formation of C-N containing compounds from reaction of a carbonyl in AS seed aerosol, but this finding is not surprising given the recent findings by De Haan et al. (2009) and the well established chemistry reported for bulk solutions.

Little experimental data are available on the physical properties of $1 \mathrm{H}$-imidazole-2-carboxaldehyde, though it is predicted to have a vapour pressure of $1.43 \times 10^{-3}$ Torr (SciFinder Scholar, 2008). Under mildly acidic conditions, this molecule would be protonated, lowering the vapour pressure and making it a viable candidate for an SOA constituent. The $\mathrm{pK}_{\mathrm{B}}$ of imidazole is 7 , so $50 \%$ will be protonated in neutral solutions. Thus at the $\mathrm{pH}$ of AS $(\sim 5)$ most of the imidazole will be protonated and the low volatility is evidenced by the fact that the carrier of the $m / z 68$ signal does not repartition to the gas phase in the dilution or irradiated experiments. The imidazole and other $\mathrm{C}-\mathrm{N}$ compounds only contribute a small amount to the total organic mass. It is possible that reaction of other $\alpha$-dicarbonyls and aldehydes could increase this contribution. However, as mentioned above, some of the reaction products of GL and AS are strongly light absorbing (Shapiro et al., 2009) and even amounts that do not add significantly to SOA mass could affect aerosol optical properties. As the imidazole is formed irreversibly, it could be used as a tracer for atmospheric carbonyl-nitrogen reactivity with implications for changing aerosol optical properties.

\subsection{Overall organic growth and glyoxal oligomer forma- tion}

Analysis of the AMS spectra collected indicates strong evidence for $\mathrm{GL}_{\mathrm{n}}$ within the aerosol (see Fig. 3). It is important to note that fragments with one or two carbons do not necessarily arise only from GL monomers in the particle phase. They can also be fragmentation products of larger oligomers; thus $\mathrm{C} 1$ and $\mathrm{C} 2$ fragments are a result of fragmentation of at least a monomer, C3 and C4 fragments are the result of fragmentation from at least a dimer, and so on. The GL and $\mathrm{GL}_{\mathrm{n}}$ mass fragments stop growing in parallel with overall organic growth and show analogous behaviour to total organic growth upon dilution. Organic growth in our study reached a plateau, providing evidence for a steady-state point, which could either be due to a depletion of a reactant in an intrinsically irreversible process or because equilibrium, with a corresponding modified effective Henry's law constant, is achieved. The dilution experiments, in which the chamber air mass was diluted with GL-free air, provide key evidence that this plateau is not caused by the depletion of a reactant. The dilution process itself reduces the gas-phase GL concentration and aerosol number density and thus total aerosol volume but does not change the composition of the aerosol phase. However, if the aerosol-phase composition was achieved via equilibrium with the gas-phase GL, reduction of the gas-phase GL concentration via dilution disturbs this equilibrium. As a result the aerosol-phase organic 
content immediately after dilution is higher than the equilibrium value for the reduced gas phase concentration would predict. The system will respond by re-partitioning GL to the gas-phase. In our dilution experiments, which reduce the gas-phase GL concentration by $25-40 \%$ (Fig. 6), the organic:sulphate ratio decreases by $15-25 \%$, which shows that organic aerosol content decreases relative to sulphate, implying a loss of GL from the aerosol phase. This shows that GL uptake onto AS aerosol is reversible; GL will partition from the aerosol to gas phase in the event of lowered gas phase concentrations in the case of reversible uptake. The fact that the aerosol phase organic content decreased a little less than the gas-phase GL concentration is expected from the (slow) kinetics.

For the dark GL uptake experiments, only C-N compounds, GL and $\mathrm{GL}_{\mathrm{n}}$ were identified, while no organosulphate was found. C-N compounds are clearly formed irreversibly since no loss from the aerosol was seen upon dilution. The fact that they only contribute a small part of the organic AMS signal and that overall organic growth as well as GL and $\mathrm{GL}_{\mathrm{n}}$ growth are reversible, suggests strongly that overall growth is dominated by GL and $\mathrm{GL}_{\mathrm{n}}$. The studies by Liggio et al. (2005a,b) were conducted on timescales $(\sim 4 \mathrm{~h})$ in which equilibrium was not yet achieved in our studies. We have therefore compared our organic growth during the first $4 \mathrm{~h}$ with that of Liggio et al. (2005a,b) for experiments at similar relative humidities of $49 \%$ (Liggio et al., 2005a,b) and 55\% (this study) and gas-phase GL concentrations of $5.1 \mathrm{ppb}_{\mathrm{v}}$ (Liggio et al., 2005a,b) and $\sim 70 \mathrm{ppb}_{\mathrm{v}}$ (this study). The organic/sulphate ratio after $4 \mathrm{~h}$ in the work by Liggio et al. (2005a) is $\sim 16$, which is more than an order of magnitude larger than in this study $(\sim 0.35)$, and we expect that the difference would have been even larger if we had employed the lower GL mixing ratios of the work by Liggio et al. $(2005 \mathrm{a}, \mathrm{b})$. Although the first two hours of our data can be interpreted with a linear slope the curvature of $2-4 \mathrm{hrs}$ in the study presented here shows a decreasing uptake rate in agreement with the fact that equilibrium is achieved after about $10 \mathrm{~h}$. It is hard to interpret a clear curvature in the work by Liggio et al. (2005a). The average aerodynamic diameter of the seed aerosol in the study by Liggio et al. (2005a) is initially smaller and thus the uptake rate per volume of seed aerosol is expected to be faster than in this study, but it is unlikely that this alone can explain the discrepancy. In a more recent study, Volkamer et al. (2009) showed that photochemical uptake was higher within $90 \mathrm{~s}$ than over several hours in our study and the study of Kroll et al. (2005). The presence of OH in the study by Volkamer et al. (2009) represents a significant difference, which could explain the large difference in uptake rate. However, we also currently cannot determine a particular reason why the non-irradiated studies potentially show two different types of uptake (irreversible and reversible) at different rates, information that is critical if understanding of these processes is to be applied to ambient studies.
Although the primary focus of this work are the condensed phase reactions of GL and the reversibility of uptake onto AS aerosol, effective Henry's Law values for GL were also calculated. Kroll et al. (2005) assumed a unit density of $1 \mathrm{~g} / \mathrm{cm}^{3}$ and used the seed volume to calculate aerosol GL concentrations. In this manner the authors obtained a value of $K_{\mathrm{H} \text {,mod }}^{*}=2.6 \times 10^{7} \mathrm{M} / \mathrm{atm}$. However, the densities of GL trimer dihydrate (in our lab) and GL aerosol derived from drying aerosolized $40 \% \mathrm{w} / \mathrm{w}$ GL solutions (D. De Haan, personal communication, 2009) have since been measured. These densities were determined to be $1.67 \mathrm{~g} / \mathrm{cm}^{3}$ and $1.71 \mathrm{~g} / \mathrm{cm}^{3}$, respectively. Therefore, the density of GL used in this work is $\rho=1.69 \mathrm{~g} / \mathrm{cm}^{3}$, which is likely a lower limit due to partial molar volume effects in solution. Using this density, we calculate an effective Henry's Law value of $3.4 \times 10^{7} \mathrm{M} / \mathrm{atm}$ for the data from Kroll et al. (2005) and a value between $4.2 \times 10^{7} \mathrm{M} / \mathrm{atm}$ and $7.0 \times 10^{7} \mathrm{M} / \mathrm{atm}$ from this study. The study by Volkamer et al. (2009) used a density of $\rho=2 \mathrm{~g} / \mathrm{cm}^{3}$ and used the fraction of seed volume corresponding to LWC to calculate a modified GL concentration. In this manner they obtained a value of $K_{\mathrm{H} \text {,mod }}^{* *}=1.65 \times 10^{8} \mathrm{M} / \mathrm{atm}$. Using this method and density, we calculate a value between $1.51 \times 10^{8} \mathrm{M} / \mathrm{atm}$ and $2.52 \times 10^{8} \mathrm{M} / \mathrm{atm}$ for our study, reflecting the experimental uncertainty. However, it should be noted that the two studies were conducted under different conditions, as the study Volkamer et al. (2009) had an OH source present, and thus the corresponding Henry's Law constants cannot be directly compared. More work is needed to determine the effect of GL concentration, AS and LWC on the effective Henry's Law constant of GL.

\subsection{Glyoxal uptake under irradiated conditions}

We present the first analysis of organic reaction products formed during irradiated GL uptake with AS seed aerosol. Within the framework of Fig. 1, the light induced reactions that are occurring should add additional product channels in the condensed phase, so a higher uptake would be expected under irradiated conditions. No $\mathrm{OH}$ source was added in our study and thus conditions are not identical to those employed by Volkamer et al. (2009). However, there is a marked difference in the fate of GL in the particle phase for the irradiated conditions compared to dark conditions in our study, even without an added $\mathrm{OH}$ source: an organosulphate and organic acids are formed. As discussed earlier, the organosulphate formation is a result of a light induced mechanism, as can be seen in the lack of organosulphate formed even in highly acidic aerosol under non-irradiated conditions.

The relative signal strength of $m / z 44$, an indicator of oxidized organic aerosol in the AMS spectra, shows that a substantial amount of oxidized organics are formed over the duration of the irradiated experiments. This is supported by the organic acids found in filter sample analysis: formic, glyoxylic and glycolic acids, the latter a disproportionation 
product of GL, all of which have smaller Henry's law constants than GL. The formic acid and glycolic acid are observed as an ester, a higher molecular weight condensation product. Although no $\mathrm{OH}$ source was added, the observation of glyoxal oxidation products strongly indicates that the irradiation resulted in radical chemistry. Whether this chemistry occurred via $\mathrm{OH}$ or some other radical mechanism cannot be ascertained. If oxidation to more volatile products, such as glyoxylic acid, is not significantly faster than condensation (e.g. the formic-glycolic acid ester, or oxidation to oxalic acid, which can form SOA), the net SOA yield under irradiated conditions should be higher than under dark conditions as additional product channels are available. These additional product channels also make Henry's law analysis of uptake inapplicable. In contrast to the study of Volkamer et al. (2009), which generally found increased uptake and uptake rate but had an $\mathrm{OH}$ source, overall organic growth was reduced under irradiated conditions in this study as compared to dark conditions. Enhanced loss of particle-phase GL in the presence of light was observed, but while it is possible that rapid oxidation to higher volatility compounds, such as formic and glyoxylic acid, and subsequent partitioning of these to the gas phase is competing with the formation of $\mathrm{GL}_{n}$ and reaction of the oxidation products to higher molecular weight compounds, it is also possible that increasing temperature upon irradiation causes significant amounts of GL to repartition to the gas phase. This is supported by the fact that the $\mathrm{O}: \mathrm{C}$ ratio started to decrease once the chambers were irradiated. As the chambers heated, GL $(\mathrm{O}: \mathrm{C}=1: 1, \mathrm{H}: \mathrm{C}=1: 1)$ and possibly high volatility glyoxal oxidation products are revolatilized to the gas phase, leaving behind irreversibly formed compounds such as imidazoles $(\mathrm{O}: \mathrm{C}=1: 4, \mathrm{~N}: \mathrm{C}=1: 2$ and $\mathrm{H}: \mathrm{C}=1: 1)$ and low volatility carboxylic acids. This loss of GL, together with the lack of loss of imidazole, explains the increase in the $\mathrm{N}: \mathrm{C}$ ratio and an increase in the $\mathrm{H}: \mathrm{C}$ ratio, both of which are seen in these experiments. It is important to note that heating the chambers does not result in efflorescence of the aerosol, as this would trap the GL within the aerosol and increase oligomer formation (Loeffler et al., 2006), which is not observed. GL photolysis in the gas phase is also possible; however, since the walls act as a substantial reservoir of GL that is at steady state with the gas phase, this is less likely. In fact, during the irradiated GL uptake experiment shown in Fig. 7, the gas-phase GL concentrations remained constant at $\sim 150 \mathrm{ppb}_{\mathrm{v}}$ throughout the experiment. A quantitative comparison of SOA yields between dark and irradiated conditions is not possible for this work due to the different experimental conditions.

\subsection{Implications to ambient aerosol}

GL and other $\alpha$-dicarbonyls, such as methylglyoxal, are common oxidation products of both biogenic and anthropogenic VOCs. The concentration of these $\alpha$-dicarbonyls is typically highest during the day and thus SOA formation under irradiated conditions should be more important than under dark conditions. However, for a detailed understanding of the processes depicted in Fig. 1 and their contribution to SOA formation under ambient conditions, it is desirable to address these processes separately, therefore an analysis of GL uptake under both dark and irradiated conditions is helpful. While uptake and aerosol phase chemistry of GL and other $\alpha$-dicarbonyls may differ, understanding GL is instructive as a model for understanding the chemistry involved in other systems for model and experimental studies. Our study shows that GL uptake involves both reversible processes, such as growth via GL monomer and oligomers, and irreversible processes, such as $\mathrm{C}-\mathrm{N}$ compound formation and oxidation reactions under irradiated conditions. The reversible processes are likely less relevant to ambient SOA formation as they will repartition GL to the gas phase upon decreasing GL gas-phase concentrations, such as night time or transport away from GL sources. However, they provide a pathway for uptake of GL into the particle phase, allowing the irreversible processes to proceed. The majority of organic growth in the chamber studies under dark conditions occurs via GL uptake with subsequent oligomer formation, but ambient GL concentrations are substantially lower (2-3 orders of magnitude), so it is less likely the organic character of the aerosol will involve multiple GL molecules such as oligomers and 1H-imidazole-2-carboxaldehyde. However, it is likely that reactions with other aldehydes will occur. Aldehydes and $\alpha$-dicarbonyls are ubiquitous, and the discovery of this new $\mathrm{C}-\mathrm{N}$ reaction pathway allows for the potential production of many different imidazole compounds. While methylglyoxal is the most abundant $\alpha$-dicarbonyl, GL is likely the most important $\alpha$-dicarbonyl for formation of imidazoles due to the fact that the Henry's law constant for GL is larger than that for methylglyoxal $\left(K_{\mathrm{H} \text {,aq, MGL }}^{*}=3.2 \times 10^{4} \mathrm{M} / \mathrm{atm}\right)$, and thus it partitions more strongly to aqueous aerosol. However, Matsunaga et al. (2004) detected higher levels of methylglyoxal than GL in ambient particulate matter, indicating that the high gas phase mixing ratios of methylglyoxal may make it an important contributor to SOA formation. As the underlying reasons for the large difference between $K_{\mathrm{H} \text {,aq }}^{*}$ and $K_{\mathrm{H} \text {,mod }}^{*}$ are not known, it is difficult to estimate the Henry's law constant for methylglyoxal for AS seed aerosol. Kroll et al. (2005) did not observe any organic growth for methylglyoxal, but the growth from imidazoles, which proceeds via an $\alpha$-dicarbonyl monomer, might have been below the detection threshold. Even small amounts of the newly discovered light absorbing compounds, in particular $\mathrm{C}-\mathrm{N}$ compounds, in aerosol can influence the optical properties of the aerosol due to their strong absorptive properties (Shapiro et al., 2009). In this context it is interesting to note that Barnard et al. (2008) found enhanced absorption of "brown carbon" aerosol in Mexico City that added about $40 \%$ absorption to that of black carbon. Imidazoles are an ideal tracer for these C-N 
compounds, due to the ubiquitous nature of their precursors, as described above. This study suggests that methods should be developed to allow analysis of field aerosol samples with respect to this class of compound, and potentially also for compounds derived from methylglyoxal, which is typically present in higher concentrations in areas in which biogenic VOC chemistry dominates (Spaulding et al., 2003). This study also shows that irradiated conditions produce oxidation products of GL even in the absence of an added OH source. However, the monomers found in this study, such as formic acid, glycolic acid and glyoxylic acids, have lower Henry's law constants than GL and thus will not necessarily increase SOA yields. An exception would be the production of oxalic acid and higher molecular weight compounds, such as organosulphates, which would increase SOA yields.

\section{Conclusions}

This study provides new insights into processes that can contribute to SOA formation from GL and the degree of reversibility of these processes. Reversibility is judged with respect to the experimental timescales, which were as long as $26 \mathrm{~h}$ after initiation of organic growth. We demonstrate that:

1. GL does not form a sulphate (i.e. organosulphate of GL) that can be detected using methods based on filter extraction. It is likely that carbonyl sulphates are in general not stable enough to be identified with filter extraction methods. Previous assignments of such compounds should be revisited,

2. $\mathrm{C}_{2} \mathrm{H}_{3} \mathrm{SO}_{6}^{-}$, which has been found in ambient samples, corresponds to glycolic acid sulphate. It is not formed under dark conditions with neutral or acidic AS seed aerosol and was only observed in irradiated experiments. The glycolic acid sulphate was identified by comparison with a laboratory synthesized standard,

3. carbon-nitrogen containing compounds form irreversibly with AS seed aerosol,

4. overall GL uptake and GL oligomer formation in the particle phase are reversible for neutral AS seed aerosol in the dark for the experimental conditions of this study,

5. there is clear evidence for active photochemistry for GL uptake under irradiated conditions, including formation of glyoxylic acid, glycolic acid, formic acid, and glycolic acid sulphate.

Further studies are required to evaluate imidazoles as tracers of carbonyl-ammonium chemistry that produces strongly light absorbing aerosol products. Studies are ongoing to elucidate the formation of condensed-phase oxidation products and, in particular, glycolic acid sulphate and the contribution of these compounds to SOA.
Acknowledgements. The authors are grateful to Tehshik Yoon for his helpful discussions about organic synthesis. This work was supported by the Camille and Henry Dreyfus Foundation, the NDSEG-ARO, the US Department of Energy grant DE-FG0205ER63 983 and US Environmental Protection Agency STAR grant RD-83 374901 . It has not been formally reviewed by EPA. The views expressed in this document are solely those of the authors and the EPA does not endorse any products in this publication. Development of the Madison-LIP instrument was supported by the National Science Foundation, Division of Atmospheric Sciences, Atmospheric Chemistry Program (grant 0724912), and the NDSEG-ARO. The Waters UPLC-LCT Premier XT time-of-flight mass spectrometer was purchased in 2006 with a grant from the National Science Foundation, Chemistry Research Instrumentation and Facilities Program (CHE-0 541 745).

Edited by: V. F. McNeill

\section{References}

Aiken, A. C., DeCarlo, P. F., and Jimenez, J. L.: Elemental analysis of organic species with Electron Ionization HighResolution Mass Spectrometry, Anal. Chem., 79, 8350-8358, doi:10.1021/ac071150w, 2007.

Aiken, A. C., DeCarlo, P. F., Kroll, J. H., Worsnop, D. R., Huffman, J. A., Docherty, K., Ulbrich, I. M., Mohr, C., Kimmel, J. R., Sueper, D., Zhang, Q., Sun, Y., Trimborn, A., Northway, M., Ziemann, P. J., Canagaratna, M. R., Onasch, T. B., Alfarra, R., Prevot, A. S. H., Dommen, J., Duplissy, J., Metzger, A., Baltensperger, U., and Jimenez, J. L.: O/C and OM/OC ratios of primary, secondary, and ambient organic aerosols with High Resolution Time-of-Flight Aerosol Mass Spectrometry, Environ. Sci. Technol., 42, 4478-4485, doi:10.1021/es703009q, 2008.

Angelino, S., Suess, D. T., and Prather, K. A.: Formation of aerosol particles from reactions of secondary and tertiary alkylamines: Characterization by aerosol time-of-flight mass spectrometry, Environ. Sci. Technol., 35, 3130-3138, doi:10.1021/es0015444, 2001.

Barnard, J. C., Volkamer, R., and Kassianov, E. I.: Estimation of the mass absorption cross section of the organic carbon component of aerosols in the Mexico City Metropolitan Area, Atmos. Chem. Phys., 8, 6665-6679, 2008,

http://www.atmos-chem-phys.net/8/6665/2008/.

Canagaratna, M. R., Jayne, J. T., Jimenez, J. L., Allan, J. D., Alfarra, M. R., Zhang, Q., Onasch, T. B., Drewnick, F., Coe, H., Middlebrook, A., Delia, A., Williams, L. R., Trimborn, A. M., Northway, M. J., DeCarlo, P. F., Kolb, C. E., Davidovits, P., and Worsnop, D. R.: Chemical and microphysical characterization of ambient aerosols with the Aerodyne Aerosol Mass Spectrometer, Mass. Spectrom. Rev., 26, 185-222, doi:10.1002/mas.20115, 2007.

Carlton, A. G., Turpin, B. J., Altieri, K. E., Seitzinger, S., Reff, A., Lim, H. J., and Ervens, B.: Atmospheric oxalic acid and SOA production from glyoxal: Results of aqueous photooxidation experiments, Atmos. Environ., 41, 7588-7602, doi:10.1016/j.atmosenv.2007.05.035, 2007.

Cho, J. R., Cho, S. G., Goh, E. M., and Kim, J. K.: Procede de preparation du 2,2,'-bi-1H-imidazole a partir du glyoxal ed d'un sel d'ammonium, 0304378, 2003. 
Cocker, D. R., Flagan, R. C., and Seinfeld, J. H.: State-of-theart chamber facility for studying atmospheric aerosol chemistry, Environ. Sci. Technol., 35, 2594-2601, doi:10.1021/es0019169, 2001.

Corrigan, A. L., Hanley, S. W., and De Haan, D. O.: Uptake of glyoxal by organic and inorganic aerosol, Environ. Sci. Technol., 42, 4428-4433, doi:10.1021/es7032394, 2008.

de Gouw, J. A., Middlebrook, A. M., Warneke, C., Goldan, P. D., Kuster, W. C., Roberts, J. M., Fehsenfeld, F. C., Worsnop, D. R., Canagaratna, M. R., Pszenny, A. A. P., Keene, W. C., Marchewka, M., Bertman, S. B., and Bates, T. S.: Budget of organic carbon in a polluted atmosphere: Results from the New England air quality study in 2002, J. Geophys. Res.-Atmos., 110, D16305, doi:10.1029/2004JD005623, 2005.

De Haan, D. O., Corrigan, A. L., Smith, K. W., Stroik, D. R., Turley, J. J., Lee, F. E., Tolbert, M. A., Jimenez, J. L., Cordova, K. E. and Ferrell, G. R.: Secondary organic aerosol-forming reactions of glyoxal with amino acids, Environ. Sci. Technol., 43, 28182824, doi:10.1021/es803534f, 2009.

Debus, H.: Ueber die einwirkung des ammoniaks auf glyoxal, Annalen der Chemie und Pharmacie, 107, 199-208, doi:10.1002/jlac.18581070209, 1858.

DeCarlo, P. F., Kimmel, J. R., Trimborn, A., Northway, M. J., Jayne, J. T., Aiken, A. C., Gonin, M., Furher, K., Horvath, T., Docherty, K. S., Worsnop, D. R., and Jimenez, J. L.: Field-deployable, high-resolution, time-of-flight aerosol mass spectrometer, Anal. Chem., 78, 8281-8289, doi:10.1021/ac061249n, 2006.

Denkenberger, K. A., Moffet, R. C., Holecek, J. C., Rebotier, T. P., and Prather, K. A.: Real-time, single-particle measurements of oligomers in aged ambient aerosol particles, Environ. Sci. Technol., 41, 5439-5446, doi:10.1021/es0703291, 2007.

Ervens, B., Carlton, A. G., Turpin, B. J., Altieri, K. E., Kreidenweis, S. M., and Feingold, G.: Secondary organic aerosol yields from cloud-processing of isoprene oxidation products, Geophys. Res. Lett., 35, L02816, doi:10.1029/2007GL031828, 2008.

Fratzke, A. R. and Reilly, P. J.: Thermodynamic and kinetic analysis of the dimerization of aqueous glyoxal, Int. J. Chem. Kinet., 18, 775-789, 1986.

Fu, T. M., Jacob, D. J., Wittrock, F., Burrows, J. P., Vrekoussis, M., and Henze, D. K.: Global budgets of atmospheric glyoxal and methylglyoxal, and implications for formation of secondary organic aerosols, J. Geophys. Res.-Atmos., 113, D15303, doi:10.1029/2007JD009505, 2008.

Gómez-González, Y., Surratt, J. D., Cuyckens, F., Szmigielski, R., Vermeylen, R., Jaoui, M., Lewandowski, M., Offenberg, J. H., Kleindienst, T. E., Edney, E. O., Blockhuys, F., Van Alsenoy, C., Maenhaut, W., and Claeys, M.: Characterization of organosulfates from the photooxidation of isoprene and unsaturated fatty acids in ambient aerosol using liquid chromatography/(-) electrospray ionization mass spectrometry, J. Mass. Spectrom., 43, 371-382, doi:10.1002/jms.1329, 2008.

Gross, D. S., Galli, M. E., Kalberer, M., Prevot, A. S. H., Dommen, J., Alfarra, M. R., Duplissy, J., Gaeggeler, K., Gascho, A., Metzger, A., and Baltensperger, U.: Real-time measurement of oligomeric species in secondary organic aerosol with the aerosol time-of-flight mass spectrometer, Anal. Chem., 78, 2130-2137, doi:10.1021/ac0601381, 2006.

Hastings, W. P., Koehler, C. A., Bailey, E. L., and DeHaan, D. O.: Secondary organic aerosol formation by glyoxal hydra- tion and oligomer formation: humidity effects and equilibrium shifts during analysis, Environ. Sci. Technol., 39, 8728-8735, doi:10.1021/es0504461, 2005.

Heald, C. L., Jacob, D. J., Park, R. J., Russell, L. M., Huebert, B. J., Seinfeld, J. H., Liao, H., and Weber, R. J.: A large organic aerosol source in the free troposphere missing from current models, Geophys. Res. Lett., 32, L18809, doi:10.1029/2005GL023831, 2005.

Huisman, A. J., Hottle, J. R., Coens, K. L., DiGangi, J. P., Galloway, M. M., Kammrath, A., and Keutsch, F. N.: Laserinduced phosphorescence for the in situ detection of glyoxal at part per trillion mixing ratios, Anal. Chem., 80, 5884-5891, doi:10.1021/ac800407b, 2008.

Ip, H. S. S., Huang, X. H. H., and Yu, J. Z.: Effective Henry's law constants of glyoxal, glyoxylic acid, and glycolic acid, Geophys. Res. Lett., 36, L01802, doi:10.1029/2008GL036212, 2009.

Jang, M. S., Czoschke, N. M., Lee, S., and Kamens, R. M.: Heterogeneous atmospheric aerosol production by acidcatalyzed particle-phase reactions, Science, 298, 814-817, doi:10.1126/science.1075798, 2002.

Keywood, M. D., Varutbangkul, V., Bahreini, R., Flagan, R. C., and Seinfeld, J. H.: Secondary organic aerosol formation from the ozonolysis of cycloalkenes and related compounds, Environ. Sci. Technol., 38, 4157-4164, doi:10.1021/es035363o, 2004.

Kielhorn, J., Pohlenz-Michel, C., Schmidt, S., and Mangelsdorf, I.: Concise International Chemical Assessment Document 57: Glyoxal, 57, 2004.

Kroll, J. H., Ng, N. L., Murphy, S. M., Varutbangkul, V., Flagan, R. C., and Seinfeld, J. H.: Chamber studies of secondary organic aerosol growth by reactive uptake of simple carbonyl compounds, J. Geophys. Res., 110, D23207, doi:10.1029/2005JD006004, 2005.

Liggio, J., Li, S., and McLaren, R.: Heterogeneous reactions of glyoxal on particulate matter: Identification of acetals and sulphate esters, Environ. Sci. Technol., 39, 1532-1541, doi:10.1021/es048375y, 2005a.

Liggio, J., Li, S., and McLaren, R.: Reactive uptake of glyoxal by particulate matter, J. Geophys. Res., 110, D10304, doi:10.1029/2004JD005113, 2005b.

Loeffler, K. W., Koehler, C. A., Paul, N. M., and De Haan, D. O.: Oligomer formation in evaporating aqueous glyoxal and methyl glyoxal solutions, Environ. Sci. Technol., 40, 6318-6323, doi:10.1021/es060810w, 2006.

Matsunaga, S., Mochida, M., and Kawamura, K.: Variation on the atmospheric concentrations of biogenic carbonyl compounds and their removal processes in the Northern Forest at Moshiri, Hokkaido Island in Japan, J. Geophys. Res., 109, D04302, doi:10.1029/2003JD004100, 2004.

Minerath, E. C. and Elrod, M. J.: Assessing the potential for diol and hydroxy sulfate ester formation from the reaction of epoxides in tropospheric aerosols, Environ. Sci. Technol., 43, 1386-1392, doi:10.1021/es8029076, 2009.

Minerath, E. C., Casale, M. T., and Elrod, M. J.: Kinetics feasibility study of alcohol sulfate esterification reactions in tropospheric aerosols, Environ. Sci. Technol., 42, 4410-4415, 2008.

Murphy, S. M., Sorooshian, A., Kroll, J. H., Ng, N. L., Chhabra, P., Tong, C., Surratt, J. D., Knipping, E., Flagan, R. C., and Seinfeld, J. H.: Secondary aerosol formation from atmospheric reactions of aliphatic amines, Atmos. Chem. Phys., 7, 2313-2337, 2007, 
http://www.atmos-chem-phys.net/7/2313/2007/.

Myriokefalitakis, S., Vrekoussis, M., Tsigaridis, K., Wittrock, F., Richter, A., Brühl, C., Volkamer, R., Burrows, J. P., and Kanakidou, M.: The influence of natural and anthropogenic secondary sources on the glyoxal global distribution, Atmos. Chem. Phys., 8, 4965-4981, 2008,

http://www.atmos-chem-phys.net/8/4965/2008/.

Na, K., Song, C., Switzer, C., and Cocker, D. R.: Effect of ammonia on secondary organic aerosol formation from alpha-pinene ozonolysis in dry and humid conditions, Environ. Sci. Technol., 41, 6096-6102, doi:10.1021/es061956y, 2007.

Na, K., Song, C., and Cocker, D. R.: Formation of secondary organic aerosol from the reaction of styrene with ozone in the presence and absence of ammonia and water, Atmos. Environ., 40, 1889-1900, doi:10.1016/j.atmosenv.2005.10.063, 2006.

Nenes, A., Pandis, S. N., and Pilinis, C.: ISORROPIA: A new thermodynamic equilibrium model for multiphase multicomponent inorganic aerosols, Aquat. Geochem., 4, 123-152, doi:10.1023/A:1009604003981, 1998.

Nozière, B., Dziedzic, P., and Córdova, A.: Products and kinetics of the liquid-phase reaction of glyoxal catalyzed by ammonium ions $\left(\mathrm{NH}_{4}^{+}\right)$, J. Phys. Chem. A, 113, 231-237, 2009.

Odum, J. R., Hoffmann, T., Bowman, F., Collins, D., Flagan, R. C., and Seinfeld, J. H.: Gas/particle partitioning and secondary organic aerosol yields, Environ. Sci. Technol., 30, 2580-2585, doi:10.1021/es950943+, 1996.

Pankow, J. F.: An absorption-model of gas-particle partitioning of organic-compounds in the atmosphere, Atmos. Environ., 28, 185-188, 1994a.

Pankow, J. F.: An absorption-model of the gas aerosol partitioning involved in the formation of secondary organic aerosol, Atmos. Environ., 28, 189-193, 1994b.

Reinhardt, A., Emmenegger, C., Gerrits, B., Panse, C., Dommen, J., Baltensperger, U., Zenobi, R., and Kalberer, M.: Ultrahigh mass resolution and accurate mass measurements as a tool to characterize oligomers in secondary organic aerosols, Anal. Chem., 79, 4074-4082, doi:10.1021/ac062425v, 2007.

Schweitzer, F., Magi, L., Mirabel, P., and George, C.: Uptake rate measurements of methanesulfonic acid and glyoxal by aqueous droplets, J. Phys. Chem. A, 102, 593-600, doi:10.1021/jp972451k, 1998.

SciFinder Scholar: Calculated using Advanced Chemistry Development (ACD/Labs) Software V8.14 for Solaris (1994-2008 ACD/Labs), last access: 26 September 2008.

Silva, P. J., Erupe, M. E., Price, D., Elias, J., Malloy, Q. G. J., Li, Q., Warren, B., and Cocker, D. R.: Trimethylamine as precursor to secondary organic aerosol formation via nitrate radical reaction in the atmosphere, Environ. Sci. Technol., 42, 4689-4696, doi:10.1021/es703016v, 2008.

Shapiro, E. L., Szprengiel, J., Sareen, N., Jen, C. N., Giordano, M. R., and McNeill, V. F.: Light-absorbing secondary organic material formed by glyoxal in aqueous aerosol mimics, Atmos. Chem. Phys., 9, 2289-2300, 2009,

http://www.atmos-chem-phys.net/9/2289/2009/.

Schulze, H.: Imidazole Synthesis, 113684, 1973.
Sorooshian, A., Varutbangkul, V., Brechtel, F. J., Ervens, B., Feingold, G., Bahreini, R., Murphy, S. M., Holloway, J. S., Atlas, E. L., Buzorius, G., Jonsson, H., Flagan, R. C., and Seinfeld, J. H.: Oxalic acid in clear and cloudy atmospheres: Analysis of data from International Consortium for Atmospheric Research on Transport and Transformation 2004, J. Geophys. Res.Atmos., 111, D23S45, doi:10.1029/2005JD006880, 2006.

Spaulding, R. S., Schade, G. W., Goldstein, A. H., and Charles, M. J.: Characterization of secondary atmospheric photooxidation products: Evidence for biogenic and anthropogenic sources, J. Geophys. Res., 108, 4247, doi:10.1029/2002JD002478, 2003.

Surratt, J. D., Gómez-González, Y., Chan, A. W. H., Vermeylen, R., Shahgholi, M., Kleindienst, T. E., Edney, E. O., Offenberg, J. H., Lewandowski, M., Jaoui, M., Maenhaut, W., Claeys, M., Flagan, R. C., and Seinfeld, J. H.: Organosulfate formation in biogenic secondary organic aerosol, J. Phys. Chem. A, 112, 8345-8378, doi:10.1021/jp802310p, 2008.

Surratt, J. D., Kroll, J. H., Kleindienst, T. E., Edney, E. O., Claeys, M., Sorooshian, A., Offenberg, J. H., Lewandowski, M., Jaoui, M., Flagan, R. C., and Seinfeld, J. H.: Evidence for organosulfates in secondary organic aerosol, Environ. Sci. Technol., 41, 517-527, doi:10.1021/es062081q, 2007.

Volkamer, R., Jimenez, J. L., San Martini, F., Dzepina, K., Zhang, Q., Salcedo, D., Molina, L. T., Worsnop, D. R., and Molina, M. J.: Secondary organic aerosol formation from anthropogenic air pollution: Rapid and higher than expected, Geophys. Res. Lett., 33, L17811, doi:10.1029/2006GL026899, 2006.

Volkamer, R., San Martini, F., Molina, L. T., Salcedo, D., Jimenez, J. L., and Molina, M. J.: A missing sink for gas-phase glyoxal in Mexico City: Formation of secondary organic aerosol, Geophys. Res. Lett., 34, L19807, doi:10.1029/2007GL030752, 2007.

Volkamer, R., Ziemann, P. J., and Molina, M. J.: Secondary Organic Aerosol Formation from Acetylene $\left(\mathrm{C}_{2} \mathrm{H}_{2}\right)$ : seed effect on SOA yields due to organic photochemistry in the aerosol aqueous phase, Atmos. Chem. Phys., 9, 1907-1928, 2009,

http://www.atmos-chem-phys.net/9/1907/2009/.

Whipple, E. B.: The structure of glyoxal in water, J. Am. Chem. Soc., 92, 7183-7186, doi:10.1021/ja00727a027, 1970.

Zhang, Q., Jimenez, J. L., Canagaratna, M. R., Allan, J. D., Coe, H., Ulbrich, I., Alfarra, M. R., Takami, A., Middlebrook, A. M., Sun, Y. L., Dzepina, K., Dunlea, E., Docherty, K. S., DeCarlo, P. F., Salcedo, D., Onasch, T., Jayne, J. T., Miyoshi, T., Shimono, A., Hatakeyama, S., Takegawa, N., Kondo, Y., Schneider, J., Drewnick, F., Borrmann, S., Weimer, S., Demerjian, K., Williams, P., Bower, K., Bahreini, R., Cottrell, L., Griffin, R. J., Rautiainen, J., Sun, J. Y., Zhang, Y. M., and Worsnop, D. R.: Ubiquity and dominance of oxygenated species in organic aerosols in anthropogenically-influenced Northern Hemisphere midlatitudes, Geophys. Res. Lett., 34, L13801, doi:10.1029/2007GL029979, 2007.

Zhou, X. and Mopper, K.: Apparent partition coefficients of 15 carbonyl compounds between air and seawater and between air and freshwater, implications for air-sea exchange, Environ. Sci. Technol., 24, 1864-1869, doi:10.1021/es00082a013, 1990. 